\title{
Extended Bifurcated Hydrogen Bonds Network Material of Copper(II) Complexes with 2-Dimethylaminomethyl-3-hydroxypyridine: Structures and Magnetic Properties
}

\author{
Sung Kwon Kang, ${ }^{\dagger}$ Hong Woo Lee, ${ }^{\ddagger}$ Nallathambi Sengottuvelan, ${ }^{a}$ and Young-Inn Kim* \\ Department of Chemistry Education and Interdisciplinary Program of Advanced Information and Display Materials, \\ Pusan National University, Pusan 609-735, Korea. E-mail yikim@pusan.ac.kr \\ ${ }^{\dagger}$ Department of Chemistry, Chungnam National University, Daejeon 305-764, Korea \\ Department of Chemistry, Pusan National University, Pusan 609-735, Korea \\ Received October 14, 2011, Accepted November 5, 2011
}

\begin{abstract}
Two novel copper(II) complexes, $\left[\mathrm{Cu}(\mathrm{dmamhp})\left(\mathrm{H}_{2} \mathrm{O}\right)_{2}\left(\mathrm{SO}_{4}\right)\right]_{\mathrm{n}}(\mathbf{1})$ and $\left[\mathrm{Cu}(\mathrm{dmamhp})\left(\mathrm{NO}_{3}\right)_{2}\left(\mathrm{H}_{2} \mathrm{O}\right)\right] \cdot \mathrm{H}_{2} \mathrm{O}(\mathbf{2})$ [dmamhp =2-dimethylaminomethyl-3-hydroxypyridine $]$ have been synthesized and structurally characterized by single crystal X-ray diffraction analysis. Compound $\mathbf{1}$ displays a double one-dimensional chains structure, in which each chain is constituted with the distorted octahedral copper(II) complex bridged through bidentate sulfate ligands resulting in a coordination polymer. The bifurcated hydrogen bonds and $\pi-\pi$ interactions play important roles in the formation of the double chains structure. On the other hand, compound 2 adopts a distorted square pyramidal geometry around copper(II) ion and exists as a discrete monomer. There are intermolecular bifurcated hydrogen bonds and $\pi-\pi$ stacking interactions between the monomeric units. The magnetic properties revealed that the paramagnetic behaviors are dominantly manifested and there are no intermolecular magnetic interactions in both compound $\mathbf{1}$ and $\mathbf{2}$.
\end{abstract}

Key Words : Copper(II) complexes, Coordination polymer, Bifurcated hydrogen bonds

\section{Introduction}

The molecular self-assembly of coordination polymers and supramolecular entities is a powerful method in the design of new materials with promising properties of potential applications such as luminescent molecular materials, ${ }^{1}$ porous framework materials, ${ }^{2}$ bioinorganics, ${ }^{3,4}$ catalysis ${ }^{5,6}$ and non-linear optical devices. ${ }^{7}$ In particular, coordination polymers with multi-dimensional structures which involve molecular units bound together by several kinds of molecular interactions have been actively investigated because of their unusual properties..$^{8-14}$

We reported two copper(II) halide complexes with 2dimethylaminomethyl-3-hydroxypyridine (dmamhp), [Cu(dmamhp) $\left.\mathrm{X}_{2}, \mathrm{X}=\mathrm{Cl}, \mathrm{Br}\right] .{ }^{15}$ The reported compounds consisted of dimeric molecules and the dimers were held together through hydrogen bonds in an unit cell. The hydroxyl group in the dmamhp ligand played an important role in forming hydrogen bonds which were directly related to crystal packing.

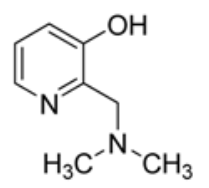

2-dimethylaminomethyl-3-hydroxypyridine(dmamhp)

As a part of our continuous interest in the coordination

${ }^{a}$ Current address: Department of Chemistry, Alagappa University, Karaikudi 630003, India properties of dmamhp ligand, we synthesize two novel $\mathrm{CuSO}_{4}$ and $\mathrm{Cu}\left(\mathrm{NO}_{3}\right)_{2}$ complexes with dmamhp : $[\mathrm{Cu}(\mathrm{dma}-$ $\left.\mathrm{mhp})\left(\mathrm{H}_{2} \mathrm{O}\right)_{2}\left(\mathrm{SO}_{4}\right)\right]_{\mathrm{n}}(\mathbf{1})$ and $\left[\mathrm{Cu}(\mathrm{dmamhp})\left(\mathrm{NO}_{3}\right)_{2}\left(\mathrm{H}_{2} \mathrm{O}\right)\right] \cdot \mathrm{H}_{2} \mathrm{O}$ (2). Compound 1 is interesting because the sulfate ligand can form a bridge between copper(II) metal centers and generate coordination polymeric chains, and few studies have been performed on sulfate bridged coordination polymers. ${ }^{16-19}$ The studied compounds show interesting structures by the existence of unusual bifurcated hydrogen bonds to extend the supramolecular arrangements. The magnetic properties were also investigated in this study.

\section{Experimental}

All reagents and solvents were purchased from Aldrich Chemical Company and used without further purification.

The direct reaction of $\mathrm{CuSO}_{4} \cdot 5 \mathrm{H}_{2} \mathrm{O}$ with 2-dimethylaminomethyl-3-hydroxypyridine (dmamhp) yielded to [Cu(dmamhp) $\left.\left(\mathrm{H}_{2} \mathrm{O}\right)_{2}\left(\mathrm{SO}_{4}\right)\right]_{\mathrm{n}}(\mathbf{1})$. An aqueous solution $(20 \mathrm{~mL})$ of $\mathrm{CuSO}_{4} \cdot 5 \mathrm{H}_{2} \mathrm{O}(1.64 \mathrm{~g}, 6.57 \mathrm{mmol})$ was added into an aqueous solution $(20 \mathrm{~mL})$ of dmamhp $(1.00 \mathrm{~g}, 6.57 \mathrm{mmol})$. The mixture was stirred for $30 \mathrm{~min}$ and changed to blue color without precipitates. Blue block crystals of $[\mathrm{Cu}(\mathrm{dmam}-$ $\left.\mathrm{hp})\left(\mathrm{H}_{2} \mathrm{O}\right)_{2}\left(\mathrm{SO}_{4}\right)\right]_{\mathrm{n}}$ suitable for X-ray single crystal diffraction were obtained on refrigeration after 10 days. Yield: 78\%. Elementary analyses were performed at the Korean Basic Science Center. Analytical data for $\mathrm{C}_{8} \mathrm{H}_{16} \mathrm{~N}_{2} \mathrm{O}_{7} \mathrm{SCu}$ : Calcd: C, 27.62; H, 4.64; N, 8.05\%. Found: C, 27.98; H, 4.88; N, 8.79\%. Selected IR (KBr): 3467 (br), 3240 (sh), 2059 (m), 1636 (s), 1299, 1114, $725 \mathrm{~cm}^{-1}$. UV-vis.: 632 (nujol), 663 nm (methanol). 
Blue needle $\left[\mathrm{Cu}(\mathrm{dmamhp})\left(\mathrm{NO}_{3}\right)_{2}\left(\mathrm{H}_{2} \mathrm{O}\right)\right] \cdot \mathrm{H}_{2} \mathrm{O}(\mathbf{2})$ crystals were obtained similarly to compound 1 using $\mathrm{Cu}\left(\mathrm{NO}_{3}\right)_{2} \cdot 3 \mathrm{H}_{2} \mathrm{O}$ in ethanol. Yield: $70 \%$. Analytical data for $\mathrm{C}_{8} \mathrm{H}_{16} \mathrm{~N}_{4} \mathrm{O}_{9} \mathrm{Cu}$ : Calcd: C, 25.57; H, 4.29; N, 14.91\%. Found: C, 25.43; H, 4.58; N, 15.53\%. Selected IR (KBr): 3467 (br), 3230 (sh), 2361 (m), 1762, 1582 (s), 1390, 1298, $1121 \mathrm{~cm}^{-1}$. UV-vis.: 620 (nujol), $674 \mathrm{~nm}$ (methanol).

The IR spectra were obtained on a Perkin-Elmer FT-IR Spectrum 2000 spectrophotometer. Electronic absorption spectra were recorded at ambient temperature on a Jasco V$570 \mathrm{UV} / \mathrm{vis} / \mathrm{NIR}$ spectrophotometer. The thermal analyses were carried out on a Mettler Toledo TGA/SDTA 851e analyzer under $\mathrm{N}_{2}$ atmosphere at a heating rate of $10{ }^{\circ} \mathrm{C} / \mathrm{min}$. The X-band EPR spectra of powdered materials were recorded at $77 \mathrm{~K}$ on an ESP-300S EPR spectrophotometer. The field modulation frequency was $100 \mathrm{kHz}$ and DPPH was used as a reference. The magnetic susceptibilities were measured on a Magnetic Property Measurement System (MPMS7) Quantum Design by SQUID method from 4 to $300 \mathrm{~K}$. The susceptibility data were corrected for the diamagnetism of the constituent atoms with Pascal's constants and for the temperature-independent paramagnetism of the copper(II) ion estimated to be $60 \times 10^{-6} \mathrm{cgsu} / \mathrm{Cu}$ atom.

X-ray intensity data were collected on a Bruker SMART APEX-II CCD diffractometer using graphite monochromated Mo K $\alpha$ radiation $(\lambda=0.71073 \AA)$. Structure was solved by applying the direct method using a SHELXS-97 and refined by a full-matrix least-squares calculation on $F^{2}$ using SHELXL-97. ${ }^{20}$ All non-hydrogen atoms were refined anisotropically. The $\mathrm{H}$ atoms on oxygen except $\mathrm{H} 7$ in compound 1 were located in a difference map and refined freely. The other $\mathrm{H}$ atoms were positioned geometrically and refined using a riding model, with $\mathrm{C}-\mathrm{H}=0.93-0.97 \AA$, and with $U_{\text {iso }}(\mathrm{H})=1.2 U_{\text {eq }}(\mathrm{C})$ for aromatic and methylene, $1.5 U_{\text {eq }}(\mathrm{C})$ for methyl $\mathrm{H}$ atoms and $1.5 U_{\mathrm{eq}}(\mathrm{O})$ for $\mathrm{H} 7$ atom in compound 1 with $\mathrm{O}-\mathrm{H}=0.82 \AA$.

Crystallographic data for the structures reported here have been deposited with the Cambridge Crystallographic Data Center (Deposition No. CCDC-613875 and 613876). The data can be obtained free of charge via www.ccdc.cam.ac.uk/ deposit (or from the CCDC, 12 Union Road, Cambridge CB2 1EZ, UK; Fax: +44-01223 336033; E-mail: deposit@ ccdc.cam.ac.uk).

\section{Results and Discussion}

Description of Structure. Single crystals of $[\mathrm{Cu}(\mathrm{dmam}-$ hp) $\left.\left(\mathrm{H}_{2} \mathrm{O}\right)_{2}\left(\mathrm{SO}_{4}\right)\right]_{\mathrm{n}}(\mathbf{1})$ and $\left[\mathrm{Cu}(\right.$ dmamhp $\left.)\left(\mathrm{NO}_{3}\right)_{2}\left(\mathrm{H}_{2} \mathrm{O}\right)\right] \cdot \mathrm{H}_{2} \mathrm{O}$ (2) were grown up from water and ethanol solution, respectively. The ORTEP views including the atomic numbering scheme are shown in Figure 1(a) and 1(b) for compound 1 and 2 , respectively. The crystallographic data and structure refinement parameters are summarized in Table 1 . The selected bond distances and bond angles are summarized in Table 2.

In compound $\mathbf{1}$, the geometry around $\mathrm{Cu}$ atom is a distorted octahedron which is surrounded by two nitrogen atoms (N1 and N9) from the bidentate dmamhp ligand and two oxygen atoms $(\mathrm{O} 1 \mathrm{~W}$ and $\mathrm{O} 2 \mathrm{~W})$ from water and two oxygen atoms of sulfate anion at the trans position. The axial $\mathrm{Cu}(\mathrm{II})-\mathrm{O} 14$ and $\mathrm{Cu}(\mathrm{II})-\mathrm{O} 12$ bond lengths are 2.603 and $2.583 \AA$, respectively, which are longer than those of the equatorial $\mathrm{Cu}(\mathrm{II})-\mathrm{O} 1$ and $\mathrm{Cu}(\mathrm{II})-\mathrm{O} 2$ of 1.991 and $1.967 \AA$, respectively. This observation is understood by Jahn-Teller distortion in $\mathrm{Cu}(\mathrm{II})$ complexes having a $\mathrm{d}^{9}$ electron configuration. The interesting feature of compound $\mathbf{1}$ is its novel double one-dimensional chain structures which are parallel to each other along $b$ axis of the unit cell in molecular packing diagram, as shown in Figure 2. The distorted octahedral copper atoms are bridged by the sulfate anion resulting in an one-dimensional chain. The planar pyridine rings are located nearly parallel to the equatorial plane of $\mathrm{Cu}$ (II) center and perpendicular to the chain extension direction. In the double chains structure, each dmamhp (a)

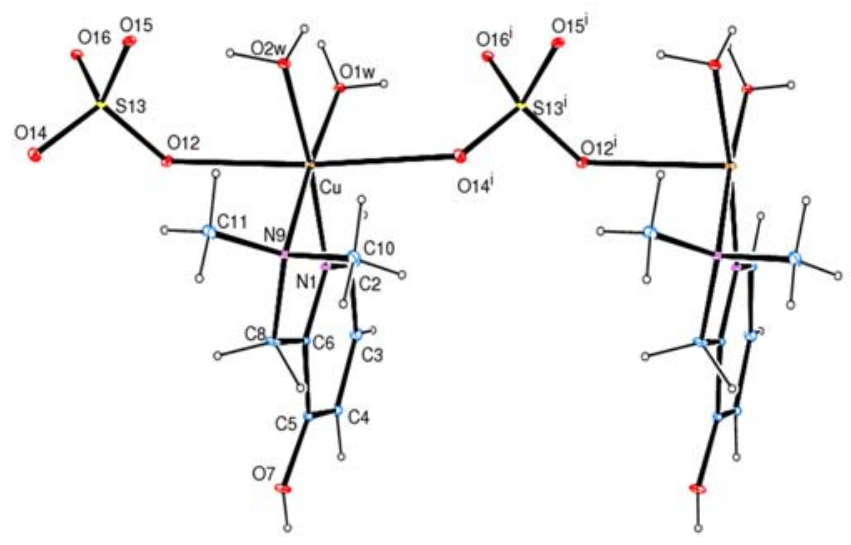

(b)

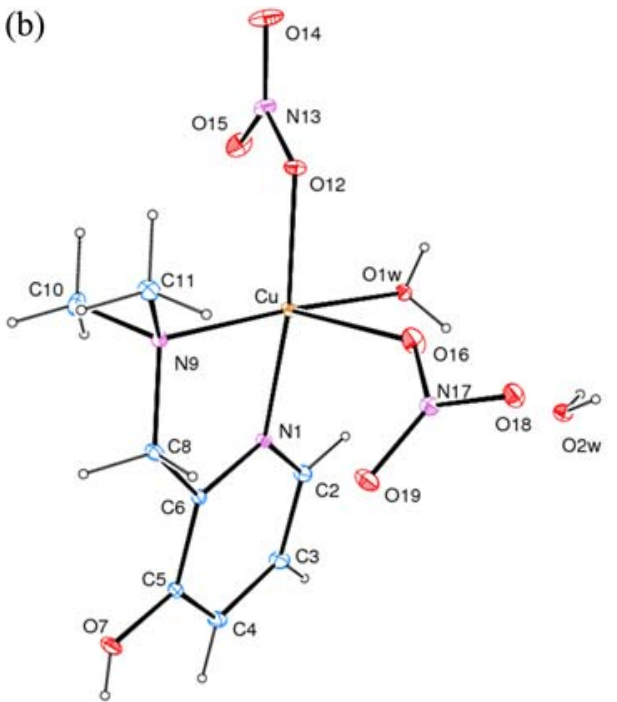

Figure 1. The molecular structures of $\left[\mathrm{Cu}(\mathrm{dmamhp})\left(\mathrm{H}_{2} \mathrm{O}\right)_{2}\left(\mathrm{SO}_{4}\right)\right]_{\mathrm{n}}$ (a) and $\left[\mathrm{Cu}(\mathrm{dmamhp})\left(\mathrm{NO}_{3}\right)_{2}\left(\mathrm{H}_{2} \mathrm{O}\right)\right] \cdot \mathrm{H}_{2} \mathrm{O}$ (b) showing the atomnumbering schemes. 
Table 1. Crystal data and structure refinement for $[\mathrm{Cu}(\mathrm{dmamhp})-$ $\left.\left(\mathrm{H}_{2} \mathrm{O}\right)_{2}\left(\mathrm{SO}_{4}\right)\right]$ and $\left[\mathrm{Cu}(\mathrm{dmamhp})\left(\mathrm{NO}_{3}\right)_{2}\left(\mathrm{H}_{2} \mathrm{O}\right)\right] \cdot \mathrm{H}_{2} \mathrm{O}$

\begin{tabular}{lll}
\hline Complexes & $\begin{array}{l}{[\mathrm{Cu}(\mathrm{dmamhp})} \\
\left.\left(\mathrm{H}_{2} \mathrm{O}\right)_{2}\left(\mathrm{SO}_{4}\right)\right]\end{array}$ & $\begin{array}{l}{[\mathrm{Cu}(\mathrm{dmamhp})} \\
\left.\left(\mathrm{NO}_{3}\right)_{2}\left(\mathrm{H}_{2} \mathrm{O}\right)\right] \cdot \mathrm{H}_{2} \mathrm{O}\end{array}$ \\
\hline Chemical formula & $\mathrm{C}_{8} \mathrm{H}_{16} \mathrm{~N}_{2} \mathrm{O}_{7} \mathrm{SCu}$ & $\mathrm{C}_{8} \mathrm{H}_{16} \mathrm{~N}_{4} \mathrm{O}{ }_{9} \mathrm{Cu}$ \\
Formula weight $(\mathrm{amu})$ & 347.83 & 375.79 \\
Crystal description & blue & Violet \\
Crystal size $(\mathrm{mm})$ & $0.20 \times 0.20 \times 0.17$ & $0.24 \times 0.20 \times 0.17$ \\
Crystal system & Monoclinic & Monoclinic \\
Space group & $P{ }_{1} / n$ & $P 2_{1} / n$ \\
$\mathrm{~T}(\mathrm{~K})$ & $293(2)$ & $295(2)$ \\
Wavelength $(\AA)$ & 0.71073 & 0.71073 \\
$a(\AA)$ and $\alpha\left({ }^{\circ}\right)$ & $7.2186(13)$ and 90.00 & $7.04600(10)$ and 90.00 \\
$b(\AA)$ and $\beta\left({ }^{\circ}\right)$ & $12.8491(11)$ and & $11.3476(2)$ and \\
& $98.938(12)$ & $97.7310(10)$ \\
$c(\AA)$ and $\gamma\left({ }^{\circ}\right)$ & $13.7369(14)$ and 90.00 & $18.5380(3)$ and 90.00 \\
Volume $\left(\AA^{3}\right)$ and $Z$ & $1258.7(3)$ and 4 & $1468.74(4)$ and 4 \\
$D_{\text {calc }}\left(\mathrm{Mg} / \mathrm{m}^{3}\right)$ & 1.836 & 1.699 \\
$\mu\left(\mathrm{mm}{ }^{-1}\right)$ & 1.932 & 1.540 \\
$\mathrm{~F}(000)$ & 716 & 772 \\
$\theta$ Range $\left({ }^{\circ}\right)$ & 11.54 to 12.55 & 2.85 to 32.33 \\
$T_{\text {max }}$ and $T_{\text {min }}$ & 0.726 and 0.659 & 0.760 and 0.689 \\
Index ranges & $-9 \leq \mathrm{h} \leq 9,0 \leq \mathrm{k} \leq 16$, & $-10 \leq \mathrm{h} \leq 10,-17 \leq \mathrm{k} \leq 14$, \\
& $0 \leq 1 \leq 17$ & $-28 \leq 1 \leq 28$ \\
Reflections collected/ & $27960 / 6849$ & $43097 / 10500$ \\
unique & {$[\mathrm{R}($ int $)=0.0354]$} & {$[\mathrm{R}(\mathrm{int})=0.0490]$} \\
Final $R$ indices & $\mathrm{R} 1=0.0235$, & $\mathrm{R} 1=0.0315$, \\
{$[I>2 \sigma(\mathrm{I})]$} & $\mathrm{wR} 2=0.0496$ & $\mathrm{wR} 2=0.0653$ \\
$\mathrm{R}$ indices $($ all data $)$ & $\mathrm{R} 1=0.0289$, & $\mathrm{R} 1=0.0593$, \\
& $w \mathrm{R} 2=0.0517$ & $\mathrm{wR} 2=0.0706$ \\
Data/Restraints/ & $6849 / 0 / 399$ & $5508 / 0 / 219$ \\
parameters & & \\
Goodness-of-fit on $\mathrm{F}^{2}$ & 1.033 & 0.863 \\
$\Delta \rho_{\text {max }}$ and $\Delta \rho_{\text {min }}\left(\mathrm{e} \AA^{-3}\right)$ & 1.500 and -0.735 & 0.321 and -0.460 \\
\hline & & \\
& &
\end{tabular}

Table 2. Selected bond lengths $(\AA)$ and angles $\left({ }^{\circ}\right)$ of $[\mathrm{Cu}-$ $($ dmamhp $\left.)\left(\mathrm{H}_{2} \mathrm{O}\right)_{2}\left(\mathrm{SO}_{4}\right)\right]_{\mathrm{n}}$ and $\left[\mathrm{Cu}(\right.$ dmamhp $\left.)\left(\mathrm{NO}_{3}\right)_{2}\left(\mathrm{H}_{2} \mathrm{O}\right)\right] \cdot \mathrm{H}_{2} \mathrm{O}$

\begin{tabular}{|c|c|c|c|}
\hline \multicolumn{2}{|c|}{ Bond distances $(\AA)$} & \multicolumn{2}{|l|}{ Bond angles $\left({ }^{\circ}\right)$} \\
\hline \multicolumn{4}{|c|}{$\left[\mathrm{Cu}(\mathrm{dmamhp})\left(\mathrm{H}_{2} \mathrm{O}\right)_{2}\left(\mathrm{SO}_{4}\right)\right]_{\mathrm{n}}$} \\
\hline $\mathrm{Cu}-\mathrm{O} 2 \mathrm{~W}$ & $1.967(4)$ & $\mathrm{O} 2 \mathrm{~W}-\mathrm{Cu}-\mathrm{N} 1$ & $174.82(17)$ \\
\hline $\mathrm{Cu}-\mathrm{N} 1$ & $1.972(4)$ & $\mathrm{O} 2 \mathrm{~W}-\mathrm{Cu}-\mathrm{O} 1 \mathrm{~W}$ & $91.69(16)$ \\
\hline $\mathrm{Cu}-\mathrm{O} 1 \mathrm{~W}$ & $1.991(4)$ & N1-Cu-O1W & $92.19(16)$ \\
\hline Cu-N9 & $2.043(4)$ & $\mathrm{O} 2 \mathrm{~W}-\mathrm{Cu}-\mathrm{N} 9$ & $91.97(16)$ \\
\hline $\mathrm{Cu}-\mathrm{O} 14$ & $2.603(4)$ & $\mathrm{N} 1-\mathrm{Cu}-\mathrm{N} 9$ & $84.32(16)$ \\
\hline $\mathrm{Cu}-\mathrm{O} 12$ & $2.583(4)$ & O1W-Cu-N9 & $175.52(18)$ \\
\hline S13-O14 & $1.447(4)$ & & \\
\hline $\mathrm{S} 13-\mathrm{O} 12$ & $1.482(4)$ & & \\
\hline S13-O16 & $1.483(4)$ & & \\
\hline $\mathrm{S} 13-\mathrm{O} 15$ & $1.484(4)$ & & \\
\hline \multicolumn{4}{|c|}{$\left[\mathrm{Cu}(\mathrm{dmamhp})\left(\mathrm{NO}_{3}\right)_{2}\left(\mathrm{H}_{2} \mathrm{O}\right)\right] \cdot \mathrm{H}_{2} \mathrm{O}$} \\
\hline $\mathrm{Cu}-\mathrm{O} 1 \mathrm{~W}$ & $1.9593(12)$ & $\mathrm{O} 1 \mathrm{~W}-\mathrm{Cu}-\mathrm{N} 1$ & $91.51(6)$ \\
\hline $\mathrm{Cu}-\mathrm{N} 1$ & $1.9774(12)$ & $\mathrm{O} 1 \mathrm{~W}-\mathrm{Cu}-\mathrm{O} 12$ & $91.76(5)$ \\
\hline $\mathrm{Cu}-\mathrm{O} 12$ & $1.9804(10)$ & $\mathrm{N} 1-\mathrm{Cu}-\mathrm{O} 12$ & $171.27(5)$ \\
\hline Cu-N9 & $2.0183(13)$ & $\mathrm{O} 1 \mathrm{~W}-\mathrm{Cu}-\mathrm{N} 9$ & $174.53(5)$ \\
\hline \multirow[t]{5}{*}{$\mathrm{Cu}-\mathrm{O} 16$} & $2.3975(12)$ & $\mathrm{N} 1-\mathrm{Cu}-\mathrm{N} 9$ & $83.31(5)$ \\
\hline & & O12-Cu-N9 & $93.12(5)$ \\
\hline & & $\mathrm{O} 1 \mathrm{~W}-\mathrm{Cu}-\mathrm{O} 16$ & $83.75(5)$ \\
\hline & & $\mathrm{N} 1-\mathrm{Cu}-\mathrm{O} 16$ & $104.00(5)$ \\
\hline & & $\mathrm{O} 12-\mathrm{Cu}-\mathrm{O} 16$ & $84.41(5)$ \\
\hline
\end{tabular}

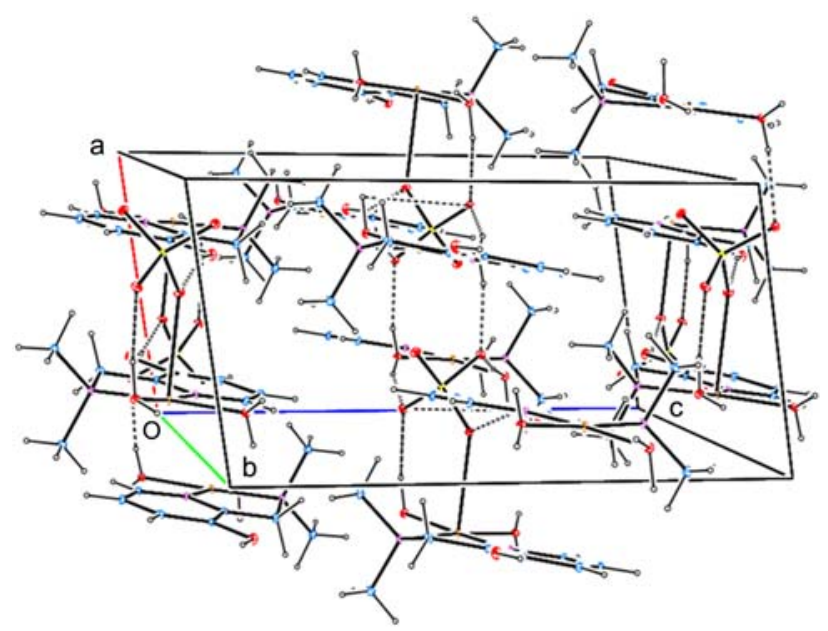

Figure 2. A molecular packing view of $\left[\mathrm{Cu}(\mathrm{dmamhp})\left(\mathrm{H}_{2} \mathrm{O}\right)_{2}-\right.$ $\left.\left(\mathrm{SO}_{4}\right)\right]_{\mathrm{n}}$ shows the bifurcated hydrogen bonds (long-dashed lines) and two double one-dimensional chains structure. $\pi-\pi$ interactions are shown with short-dashed lines.

ligand on a mono-chain is inserted into the interspaces between the closest two dmamhp ligands of the other monochain. Obviously, such double chains structure in compound 1 results in that all molecular planes of dmamhp are nearly parallel to each other. These are linked by the intermolecular $\pi-\pi$ interactions (centroid-centroid distances $=3.561-3.661$ $\AA$ ) between the C4-C5-C6 planes of aromatic rings. Additionally, there are two types of hydrogen bonding interactions in compound $\mathbf{1}$ (dashed line in Figure 2). The rare bifurcated hydrogen bonds $\mathrm{s}^{21,22}$ are observed between waters and $\mathrm{O}$ atoms of sulfate. The -OH group of dmamhp ligand also forms hydrogen bond with $\mathrm{O}$ atoms of sulfate. The hydrogen bond distances and angles are summarized in

Table 3. The bond lengths $(\AA)$ and bond angles $\left({ }^{\circ}\right)$ of hydrogen bond for $\left[\mathrm{Cu}(\mathrm{dmamhp})\left(\mathrm{H}_{2} \mathrm{O}\right)_{2}\left(\mathrm{SO}_{4}\right)\right]$ and $\left[\mathrm{Cu}(\mathrm{dmamhp})\left(\mathrm{NO}_{3}\right)_{2}-\right.$ $\left.\left(\mathrm{H}_{2} \mathrm{O}\right)\right] \cdot \mathrm{H}_{2} \mathrm{O}$

\begin{tabular}{|c|c|c|c|c|}
\hline \multicolumn{5}{|c|}{$\left[\mathrm{Cu}(\mathrm{dmamhp})\left(\mathrm{H}_{2} \mathrm{O}\right)_{2}\left(\mathrm{SO}_{4}\right)\right]_{\mathrm{n}}$} \\
\hline D-H...A & $d(D-H)$ & $\mathrm{d}(\mathrm{H} \ldots \mathrm{A})$ & $\mathrm{d}(\mathrm{D} \ldots \mathrm{A})$ & $\angle(\mathrm{DHA})$ \\
\hline O1W-H1WA...O16 & $0.79(8)$ & $1.90(8)$ & $2.676(6)$ & $167(8)$ \\
\hline O1W-H1WA...O14 & $0.79(8)$ & $2.65(8)$ & $3.057(6)$ & $115(6)$ \\
\hline $\mathrm{O} 1 \mathrm{~W}-\mathrm{H} 1 \mathrm{WB} . . . \mathrm{O} 15^{i}$ & $0.81(8)$ & $1.92(9)$ & $2.697(5)$ & $161(8)$ \\
\hline $\mathrm{O} 2 \mathrm{~W}-\mathrm{H} 2 \mathrm{WA} \ldots \mathrm{O} 15^{i i}$ & $0.91(7)$ & $1.75(7)$ & $2.661(6)$ & $171(6)$ \\
\hline $\mathrm{O} 2 \mathrm{~W}-\mathrm{H} 2 \mathrm{WB} \ldots \mathrm{O} 16^{i}$ & $0.71(7)$ & $1.98(7)$ & $2.662(5)$ & $161(8)$ \\
\hline $\mathrm{O} 7-\mathrm{H} 7 \ldots \mathrm{O} 12^{i i i}$ & 0.82 & 1.89 & $2.667(5)$ & 157.7 \\
\hline
\end{tabular}

※ symmetry code: (i) $-x+1,-y+1,-z+1$, (ii) $x-1, y, z$, (iii) $-x+1,-y,-z+1$

$\left[\mathrm{Cu}(\right.$ dmamhp $\left.)\left(\mathrm{NO}_{3}\right)_{2}\left(\mathrm{H}_{2} \mathrm{O}\right)\right] \cdot \mathrm{H}_{2} \mathrm{O}$

\begin{tabular}{lllll}
\hline $\mathrm{O} 7-\mathrm{H} 7 \ldots \mathrm{O} 2 \mathrm{~W}^{i}$ & $0.731(18)$ & $1.979(19)$ & $2.7026(18)$ & $170(2)$
\end{tabular}

O1W-H1WA...O2W $0.79(2) \quad 1.99(2) \quad 2.753(2) \quad 164(2)$

O1W-H1WB...O16 ${ }^{i i} \quad 0.70(2) \quad 2.62(2) \quad 3.1212(18) 131.1(19)$

O1W-H1WB...O18 ${ }^{i i} \quad 0.70(2) \quad 2.06(2) \quad 2.7519(18) 173(2)$

O2W-H2WA...O18 ${ }^{i i i} \quad 0.76(2) \quad 2.12(2) \quad 2.871(2) \quad 170(2)$

O2W-H2WA...O19 $9^{i i i} \quad 0.76(2) \quad 2.48(2) \quad 3.009(2) \quad 127.6(17)$

$\mathrm{O} 2 \mathrm{~W}-\mathrm{H} 2 \mathrm{WB} \ldots \mathrm{O} 12^{i i} \quad 0.71(2) \quad 2.10(2) \quad 2.8039(18) 168(2)$ 


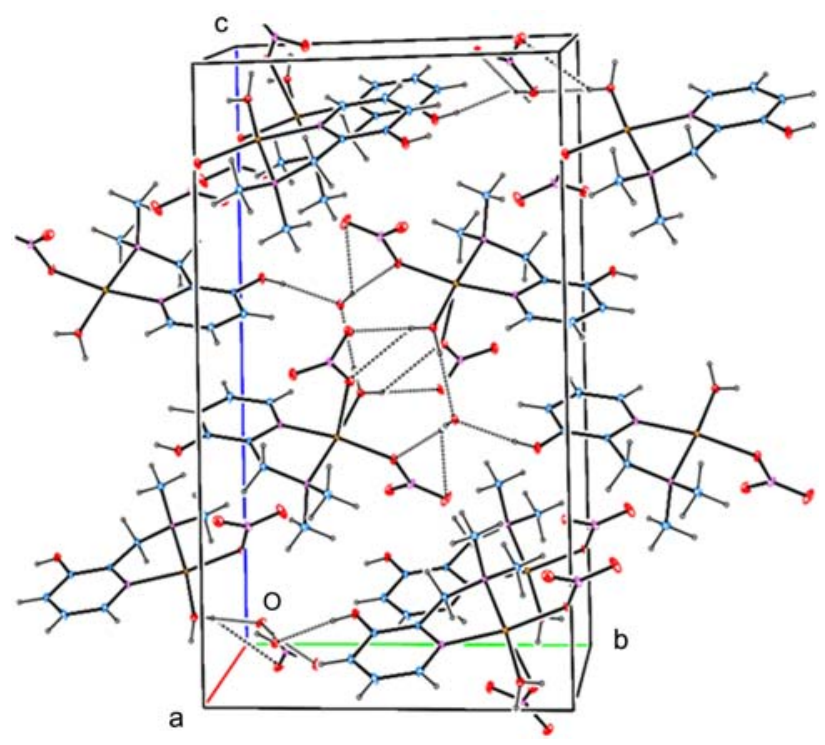

Figure 3. A molecular packing view of $\left[\mathrm{Cu}(\mathrm{dmamhp})\left(\mathrm{NO}_{3}\right)_{2}\right.$ $\left.\left(\mathrm{H}_{2} \mathrm{O}\right)\right] \cdot \mathrm{H}_{2} \mathrm{O}$ shows the bifurcated hydrogen bonds (long-dashed lines). $\pi-\pi$ interactions are shown with short-dashed.

Table 3. The hydrogen bonding interactions give rise to a supramolecular network having well-defined channels. Both $\pi-\pi$ interactions and various hydrogen bonds stabilize the molecules and play important roles in formation of double chains structure.

The $\mathrm{Cu}$ (II) metal ion in compound $\mathbf{2}$ adopts a distorted square pyramidal geometry, being coordinated by the bischelating $\mathrm{N}$-heterocyclic dmamhp ligand, two $\mathrm{O}$ atoms from two nitrate ions and one water, as shown in Figure 1(b). There is one uncoordinated water molecule in the crystal lattice. In the crystal, the intermolecular $\mathrm{O}-\mathrm{H} \cdots \mathrm{O}$ hydrogen bonds link the molecules into a two-dimensional array parallel to the $a b$ plane (Table 3 and Figure 3). A molecular packing diagram in Figure 3 shows the intermolecular hydrogen bonding interactions (dashed lines). Also, there are intermolecular $\pi-\pi$ interactions between aromatic rings. The distance between the centroids of C3-C4-C5 planes is 3.577 $\AA$. The water bound to $\mathrm{Cu}$ (II) metal forms bifurcated hydrogen bonds with $\mathrm{O}$ atoms of nitrate ions. The hydroxyl group of dmamhp ligand also forms a hydrogen bond with free water molecule.

Thermal and Magnetic Properties. Thermogravimetric (TG) analysis revealed that the thermal decomposition of compound 1 was initiated between 141 and $161^{\circ} \mathrm{C}$ by weight loss of $9.46 \%$ corresponding to the loss of two coordinated water molecules (calc. 10.36\%). There was further $\sim 36 \%$ weight loss decomposition at $253-277^{\circ} \mathrm{C}$ followed by a gradual weight loss up to $\sim 700{ }^{\circ} \mathrm{C}$. Compound 2 showed that one hydrated water and one coordinated water molecule were decomposed between 78 and $102{ }^{\circ} \mathrm{C}$ in one step. The release of one coordinated $\mathrm{NO}_{3}$ anion was observed at 176$190{ }^{\circ} \mathrm{C}$ by $16.50 \%$ weight loss (calc. $17.60 \%$ ), and the further thermal decompositions were followed in three continuous steps up to $\sim 700{ }^{\circ} \mathrm{C}$.

The EPR spectrum of compound $\mathbf{1}$ did not show a hyperfine structure with the values of $\mathrm{g}_{\|}=2.299$ and $\mathrm{g}_{\perp}=$ 2.076 in solid state at $77 \mathrm{~K}$, which was consistent with that $\mathrm{Cu}$ (II) center had an elongated octahedral geometry. ${ }^{23}$ These observed $\mathrm{g}$ values $\left(\mathrm{g}_{\|}>\mathrm{g}_{\perp}>2.0023\right)$ indicate that $\mathrm{Cu}(\mathrm{II})$ metal has a $\mathrm{d}_{\mathrm{x} 2-\mathrm{y} 2}$ ground state. ${ }^{24}$ Compound $\mathbf{2}$ exhibited an isotropic feature, $<\mathrm{g}>=2.108$, in solid state at $77 \mathrm{~K}$.

The temperature-dependent molar magnetic susceptibilities of compound 1 and $\mathbf{2}$ were measured from 4 to $300 \mathrm{~K}$. The $\chi_{m}$ value increases slowly as the temperature decreases and the $\chi_{m}$ values below $50 \mathrm{~K}$ show a sudden increase for both complexes. The data follow Curie-Weiss law of the form of $\mu_{\mathrm{eff}}=\mathrm{C} /(\mathrm{T}-\theta)$. The best linear fit of $1 / \chi_{\mathrm{m}}$ versus temperature results in a Curie-Weiss temperature of $\theta=\quad-$ $0.13 \mathrm{~K}$ and a Curie constant of $C=0.464 \mathrm{~cm}^{3} \mathrm{~K} \mathrm{~mol}^{-1}$ for compound 1 , and $\theta=0.39 \mathrm{~K}$ and $C=0.465 \mathrm{~cm}^{3} \mathrm{~K} \mathrm{~mol}^{-1}$ for compound 2. These obtained small Curie-Weiss temperatures indicate that the magnetic interactions between the copper (II) ions are almost negligible in both compound $\mathbf{1}$ and 2. An analogous $\left[\mathrm{Cu}(\mathrm{phen})\left(\mathrm{H}_{2} \mathrm{O}\right)_{2} \mathrm{SO}_{4}\right]_{\mathrm{n}}$ (phen=phenanthroline) compound with 1 was reported to have a similar polymeric chain structure. ${ }^{25}$ The spin-orbital exchange coupling constant, $J$, of $-3.8 \mathrm{~cm}^{-1}$ was calculated on the basis of the measured magnetic data. It indicated that there was weak antiferromagnetic interactions between the magnetic orbitals of copper(II) atom through the sulfate bridge in $[\mathrm{Cu}($ phen)$\left.\left(\mathrm{H}_{2} \mathrm{O}\right)_{2}\left(\mathrm{SO}_{4}\right)\right]_{\mathrm{n}}$ compound. But no magnetic interactions were observed in compound 1 . This result can be explained by the fact that the $\mathrm{Cu}-\mathrm{O}$ (sulfate ion) distance of 2.583 and 2.603 $\AA$ in compound $\mathbf{1}$ is too long to interact magnetically between spin only copper(II) centers through sulfate ion, comparing to those of $\left[\mathrm{Cu}(\text { phen })\left(\mathrm{H}_{2} \mathrm{O}\right)_{2}\left(\mathrm{SO}_{4}\right)\right]_{\mathrm{n}}$ complex with the $\mathrm{Cu}-\mathrm{O}$ (sulfate ion) distance of 2.454(9) and 2.478(9) $\AA$. The effective magnetic moment $\left(\mu_{\text {eff }}\right)$ values at $300 \mathrm{~K}$ calculated from the equation, $\mu_{\mathrm{eff}}=2.828\left(\chi_{\mathrm{m}} \times \mathrm{T}\right)^{1 / 2}$, were 1.91 and 1.92 $\mu_{\mathrm{B}}$ for compound $\mathbf{1}$ and $\mathbf{2}$, respectively, which were higher than that of spin only value of single copper(II) ion with $\mathrm{S}=$ $1 / 2\left(\mu_{\mathrm{eff}}=1.73 \mu_{\mathrm{B}}\right)$ system.

\section{Conclusion}

Two copper(II) complexes, $\left[\mathrm{Cu}(\mathrm{dmamhp})\left(\mathrm{H}_{2} \mathrm{O}\right)_{2}\left(\mathrm{SO}_{4}\right)\right]_{\mathrm{n}}$ (1) and $\left[\mathrm{Cu}(\mathrm{dmamhp})\left(\mathrm{NO}_{3}\right)_{2}\left(\mathrm{H}_{2} \mathrm{O}\right)\right] \cdot \mathrm{H}_{2} \mathrm{O}$ (2) have been synthesized, and structurally and magnetically characterized. These compounds possess the bifurcated hydrogen bonds and $\pi-\pi$ stacking interactions which stabilize the molecule frameworks. Compound $\mathbf{1}$ has double one-dimensional chain networks which are parallel to each other and form a coordination polymer. The hydrogen bonds give rise to a supramolecular network having well-defined channel. The compound 1 and $\mathbf{2}$ follow Curie-Weiss behavior with the small Curie-Weiss temperature suggesting that there are no significant magnetic interactions between the magnetic orbitals of $\mathrm{Cu}(\mathrm{II})$ atom. The studied compounds act as isolated paramagnetic systems.

Acknowledgments. This work was supported by Basic Science Research Program through the National Research 
Foundation of Korea (NRF) funded by the Ministry of Education, Science and Technology (No. 20110003799).

\section{References}

1. Natale, D.; Mareque-Rivas, J. C. Chem. Commun. 2008, 425.

2. Khan, M. I.; Cevik, S.; Doedens, R. J. Chem. Commun. 2001, 1930.

3. Tamasi, G.; Cini, R. Dalton Trans. 2003, 2928.

4. Reedijk, J. Inorg. Chim. Acta 1992, 198-200, 873.

5. Maheswaran, S.; Chastanet, G.; Teat, S. J.; Mallah, T.; Sessoli, R.; Wernsdorfer, W. Anrew. Chem, Int. Ed. 2005, 44, 5044.

6. Lee, J. Y.; Farha, O. K.; Roberts, J.; Scheidt, K. A.; Nguyen, S. T.; Hupp, J. T. Chem. Soc. Rev. 2009, 1450, 38

7. Zang, S.; Su, Y.; Li, Y.; Ni, Z.; Meng, Q. Inorg. Chem. 2006, 174, 45 .

8. Kawata, S.; Kitagawa, S.; Kumagai, H.; Kudo, C.; Kamesaki, H.; Ishiyama, T.; Suzuki, R.; Kondo, M.; Katada, M. Inorg. Chem. 1996, 35, 4449.

9. Kawata, S.; Kitagawa, S.; Machida, H.; Nakamoto, T.; Kondo, M.; Katada, M.; Kikuchi, K.; Ikemoto, I. Inorg. Chim. Acta 1995, 229, 211.

10. Kawata, S.; Kumagai, H.; Kitagawa, S.; Honda, K.; Enomoto, M.; Katada, M. Mol. Cryst. Liq. Cryst. 1996, 51, 286.
11. Breeze, S. R.; Wang, S. Inorg. Chem. 1993, 32, 5982.

12. Robl, C.; Hentschel, S.; Mclntyre, G. Solid State Chem. 1992, 96, 318.

13. Margues, L. F.; Marinho, M. V.; Correa, C. C.; Speziali, N. L.; Diniz, R.; Machado, F. C. Inorg. Chim. Acta 2011, 242, 368.

14. Johnston, L. L.; Nettleman, J. H.; Braverman, M. A.; Sposato, L. K.; Supkowski, R. M.; Laduca, R. L. Polyhedron 2010, 29, 303.

15. Lee, Y.-M.; Lee, H.-W.; Kim, Y.-I. Polyhedron 2005, 24, 377.

16. Tao, J.; Zhang, Y.; Tong, M.; Chen, X.; Yuen, T.; Lin, C. L.; Huang, X.; Li, J. Chem. Commun. 2002, 13, 1342.

17. Lu, Y. J.; Babb, A. M. Inorg. Chem. 2001, 40, 3261.

18. Shi, Z.; Feng, S.; Sun, Y.; Hua, J. Inorg. Chem. 2001, 40, 5312.

19. Garmez, P.; Hoog, P.; Roubeau, O.; Lutz, M.; Driessen, W. L.; Spek, A. L.; Feedijk, J. Chem. Commun. 2002, 1488.

20. Sheldrick, G. M. Acta Cryst. 2008, A64, 112.

21. Choi, S.-N.; Lee, Y.-M.; Lee, H.-W.; Kang, S. K.; Kim, Y.-I. Acta Cryst. 2002, E58, m583.

22. Oliveira Legendre, A.; Mauro, A. E.; Oliveira, M. A. R.; Prado Gambardella, M. T. Inorg. Chem. 2008, 11, 896.

23. Kolarz, B. N.; Trochimczuk, A. W.; Jermakowicz-Bartkowiak, D.; Jezierska, J. Polymer 2002, 43, 1062.

24. Kang, S. K.; Kim, H.-S.; Kim, Y.-I. Bull. Korean. Chem. Soc. 2004, $25,1959$.

25. Xu, L.; Wang, E.; Peng, J.; Huang, R. Inorg. Chem. Commun. 2003, 6, 740 . 